\title{
Sign of the times: the Milligan-Morgan era
}

\author{
Gaetano Gallo ${ }^{1,2}\left(\mathbb{D} \cdot\right.$ Alberto Realis Luc $^{2} \cdot$ Vincenzo Tiesi $^{1,2} \cdot$ Mario Trompetto $^{1}$
}

Received: 24 March 2021 / Accepted: 12 May 2021 / Published online: 17 May 2021

(c) Springer Nature Switzerland AG 2021

A 68-year-old man presented to our outpatient clinic with a history of faecal incontinence.

The patient had had a typical three-piles Milligan-Morgan haemorrhoidectomy 25 years earlier for grade III haemorrhoids. Furthermore, a posterior sphincterotomy, resulting in a key-hole deformity, had been performed (Fig. 1). His medical history was unremarkable. Anorectal manometry showed a reduction in both rest and squeeze sphincter pressures associated with impaired rectoanal coordination. Endoanal ultrasound showed an internal sphincter injury.

The patient underwent sacral neurostimulation, through the S3 sacral foramen, with a $65 \%$ improvement of the faecal incontinence.

Open excisional haemorrhoidectomy marked the twentieth century and is still the gold standard for grade III and grade IV haemorrhoids [1]. However, a step-up-approach avoiding an unnecessary removal of the piles as well as the potential side effects, such as a poor sphincter function or anal stenosis, should be considered especially considering the current technological evolution and the less invasive options [1]. Posterior sphincterotomy should be discouraged.

Acknowledgements This research received no specific grant from any funding agency in the public, commercial, or not-for-profit sectors. All the authors contributed equally to this work, satisfying the four criteria of the guidelines of the International Committee of Medical Journal Editors (ICMJE).

\section{Declarations}

Conflict of interest The authors declare that they have no conflicts of interest.

Ethical approval All procedures performed in studies involving human participants were in accordance with the ethical standards of the insti-

Gaetano Gallo

gallog@unicz.it

1 Department of Medical and Surgical Sciences, University of Catanzaro, Catanzaro, Italy

2 Department of Colorectal Surgery, S. Rita Clinic, Vercelli, Italy

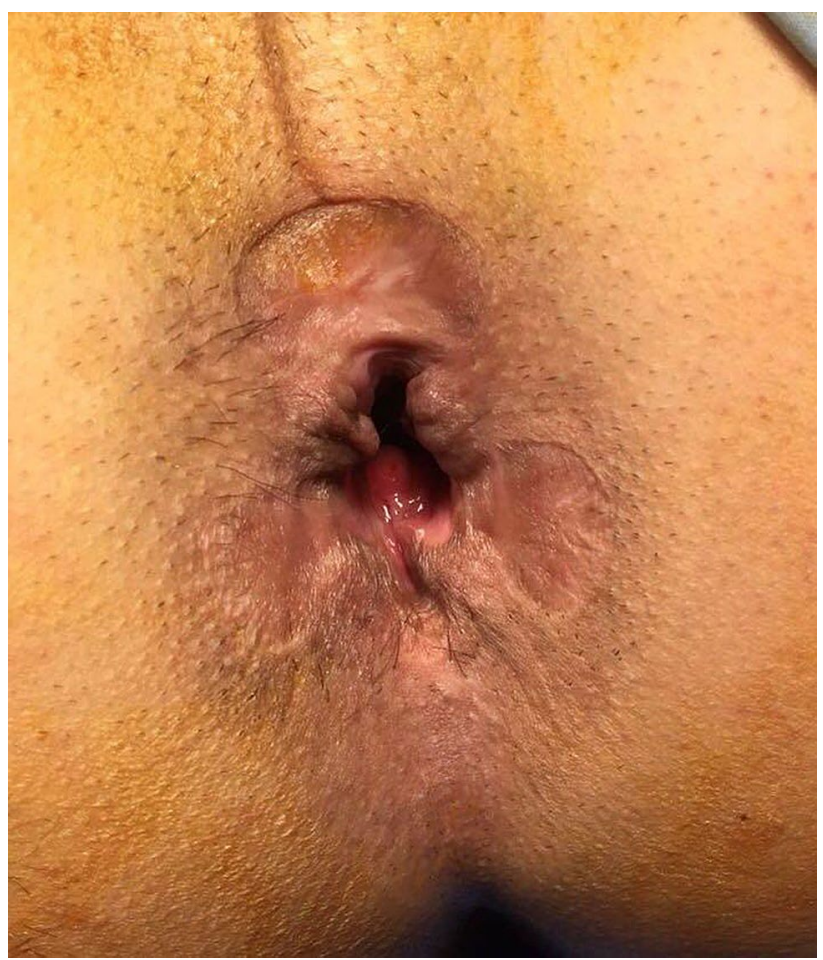

Fig. 1 Sequelae of a three-piles Milligan-Morgan haemorrhoidectomy with posterior sphincterotomy

tutional and/or national research committee and with the 1964 Helsinki declaration and its later amendments or comparable ethical standards.

Informed consent Informed consent was obtained from the participant included in the study.

\section{Reference}

1. Gallo G, Martellucci J, Sturiale A et al (2020) Consensus statement of the Italian society of colorectal surgery (SICCR): management and treatment of hemorrhoidal disease. Tech Coloproctol 24(2):145-164. https://doi.org/10.1007/s10151-020-02149-1

Publisher's Note Springer Nature remains neutral with regard to jurisdictional claims in published maps and institutional affiliations. 